\title{
La crítica de la Moral Kantiana desde Nietzsche
}

\author{
Elena Calvo*
}

Recibido: diciembre 2010 - Aceptado: febrero 2011

\begin{abstract}
RESUMEN
En este ensayo se intenta esbozar la crítica de Nietzsche a los tres conceptos de gran importancia en la ética y moral kantianas: el sujeto, la libertad y el imperativo categórico y propiciar así la discusión sobre la posible limitación de la visión de Kant.
\end{abstract}

Palabras clave: Nietzsche, Kant, moral, sujeto, libertad imperativo categórico.

\begin{abstract}
This essay attempts to outline Nietzsche's critique of the three concepts of great importance in Kantian ethics and morality: the subject, freedom and the categorical imperative and thus promote discussion on the possible limitation of Kant's point of view.
\end{abstract}

Key words: Nietzsche, Kant, morality, subject, freedom, cathegorical imperative.

\section{Relación de Nietzsche con Kant}

No se sabe con certeza si Nietzsche leyó directamente alguna obra de Kant o si sólo accedió a él mediante las críticas schopenhauerianas, las obras de Friedrich
Albert Lange, Gustav Teichmuller, Otto Leibman y el Kant de Kuno Fisher, con lo cual su conocimiento del autor de las Críticas se reduciría considerablemente y probablemente distorsionaría su interpretación. Sin embargo, la obsesión que tiene

* Licenciada en Filología Clásica, docente en la Universidad de Costa Rica; calvelena@gmail.com 
Nietzsche con Kant a lo largo de todas sus obras, el interés exagerado, y el detallismo de las citas, nos hacen pensar que fue, un lector atento de este autor, aunque también un lector ciertamente prejuiciado.

La actitud de Nietzsche hacia Kant fue ambigua. En El nacimiento de la tragedia lo saluda como el pensador que superó el "optimismo" tanto religioso como científico: las verdades universalísimas (el concepto de Dios y los conceptos que pretenden explicar la realidad) son bajadas desde su pedestal y consideradas aparenciales. Sin embargo, pronto se decepciona: se elimina a Dios como verdad, pero se lo reintroduce como postulado; la metafísica es desprestigiada, pero la producción de la realidad por el sujeto no es vista como "el velo del Maya" (la apariencia como el mal que no nos deja conocer la realidad tal cual), sino como la realidad del ser humano y su verdad. Es por ello que Nietzsche llama a Kant "cant" (hipócrita en inglés), "chino", el mediocre1, y a su filosofía "la

1. Nietzsche usa de vez en cuando la palabra "chino" y "chinerías" para decir 'mediocre' y 'mediocridades', respectivamente, puesto que, en general consideraba a las culturas orientales como mediocres, autosatisfechas y rígidamente moralizantes, En Voluntad de Poder llama a la moral china: la expresión de la regresión fisiológica. Fuente: Palmquist, Steve. How "chinese" was Kant? Recuperado el 11 de noviembre del 2011 de http:// www.the-philosopher.co.uk/chinese.htm. filosofía de las puertas traseras", es decir la que por un lado echa a la metafísica y a la teología y por la parte de atrás las vuelve a introducir disfrazadas de sujeto trascendente y de imperativo categórico. En Gaya ciencia Nietzsche compara a Kant con una zorra que, habiendo roto los barrotes de la jaula con su fuerza e ingenio, se vuelve a meter en su prisión, por error.

Nietzsche es consciente de la importancia del filósofo königsberguense en la filosofía alemana y, en general, en la filosofía occidental moderna. Él ve en Kant un gran logro del pensamiento: la crítica a la metafísica, y el entendimiento de la filosofía como una crítica que debe ser total. Por lo tanto es un "rival digno de combate", Nietzsche jamás lo mencionaría si lo creyera vacuo o sin importancia, el hecho de que lo deteste, es un indicio del gran respeto que le profesa (se puede encontrar una referencia a lo que Nietzsche llamaría un enemigo digno en Ecce Homo: "yo solo ataco causas victoriosas"). Mas no lo considera un filósofo auténtico, sino un compilador de los valores existentes, uno muy necesario, para dar el salto, para despertar del "sueño dogmático", pero peligroso si se sigue al pie de la letra. ¿En qué consiste tal peligro? Pues, en que al dar la ilusión de liberación de los prejuicios religiosos y metafísicos de antaño, se queda en el prejuicio 
de la razón. Sí, en efecto, para Nietzsche, la razón es un prejuicio más, este, hábilmente disfrazado de verdad, quiere regir las acciones humanas. Pero es "solo una mentira que se ha olvidado de que lo es", como se demuestra en Sobre la verdad y mentira en el sentido extramoral $^{2}$. Es como escapar de prisión siguiendo a un guía que se erige en tirano. Sería una libertad incompleta y finalmente nula. De la misma forma la razón es un instrumento que destrona a la metafísica, $y$ al final debe ser criticada y anulada como poder ella misma. Mas en Kant este paso no se da. Al criticar a Kant, Nietzsche lo supera en este sentido, pone en evidencia el hecho de que la razón también es cuestionable y no puede dar los parámetros últimos para juzgar las cosas, puesto que ella misma depende de algo. ¡Depende del cuerpo!

De aquí también se desprende el hecho de que hablamos de un ataque a la moral más que a la ética, aunque usemos los conceptos de esta última. Precisamente porque la ética se sigue de la moral concreta de una persona y los parámetros mediante los cuales Kant pretende juzgar a los demás, son las

2. Ver el texto en su totalidad: Nietzsche, Friedrich (1970). Sobre verdad y mentira en sentido extramoral, Obras Completas, vol. I, Buenos Aires: Ediciones Prestigio. condiciones de su propio cuerpo, de las limitaciones y virtudes del "sí mismo" que él es.

\section{El "Chino de Königsberg”}

La razón práctica sólo es posible si detrás de la acción existe efectivamente un sujeto. Y que éste puede actuar coaccionado por su propia razón, proyectarse hacia fuera de la naturaleza, es decir hacia la libertad. Nietzsche pone en duda la existencia de un sujeto detrás de los actos, por una parte $y$, por otra, la posibilidad de proyectarse fuera de la naturaleza y de ser responsable de sus acciones, así como universalizarlas en un imperativo categórico. Finalmente, le cuestiona a Kant su unilateralidad como pensador.

\section{Contra el sujeto}

Este punto Nietzsche no lo relaciona con Kant directamente, pero quiero mencionarlo porque conscientemente o no, con éste se da el primero y el último golpe a la filosofía de Kant y en general a la filosofía moderna.

Para Nietzsche el "yo" es un engaño de la gramática. Decimos "yo pienso" o "yo actúo" y creemos ciegamente que esa unidad ("yo") que vemos en el papel actúa como tal en el pensar. Sin embargo, de lo que "se piensa en mí", aprehendo 
y concientizo apenas una ínfima parte. Es decir, el control presunto de mi "pensar" por parte del "yo" es mera apariencia. "Ello piensa", "algo piensa en mí", dice Nietzsche, "algo", del que "yo" es apenas la punta del iceberg.

Dices "yo" y estás orgulloso de esa palabra. Pero esa cosa aun más grande, en la que tú no quieres creer, _tu cuerpo y su gran razón: esa no dice yo, pero hace yo.

El cuerpo es una gran razón, una pluralidad dotada de un único sentido, una guerra y una paz, un rebaño y un pastor. (Nietzsche, 2000)

El "yo" se revela como una ilusión de unidad, como una pluralidad irreconciliable que actúa como uno, pero no determinada por la voluntad única, sino por muchas causas ajenas a nuestra conciencia subjetiva. De allí que el sujeto que actúa dándose la norma es ilusorio, porque la orden consciente y bien pensada del sujeto, es sólo la consecuencia de la multiplicidad de causas que actúan "por debajo" de su conciencia (deseos, miedos, frustraciones, etc., que a su vez son afectadas por causas como la raza, la cultura, el clima, el alimento, etc.).

\section{Contra la libertad}

A partir de lo anterior, no podríamos hablar más de la responsabilidad moral, esto se precisa en el parágrafo 39 de Humano demasiado humano:

Este ser mismo [el del hombre] no puede ser responsable, por ser una consecuencia necesaria y absolutamente determinada por elementos $e$ influencias de objetos presentes y pasados; por lo tanto que el hombre no es responsable de nada, ni de su ser, ni de sus motivos, ni de sus actos, ni de su influencia. (Nietzsche, 1962)

Por lo anterior, que no podemos hablar de la libertad, pues nuestros actos están determinados por las fuerzas múltiples y subconscientes que habitan nuestro cuerpo. La libertad moral es un error. Nietzsche describe la genealogía de este error en el mismo parágrafo:

- Lo bueno/ lo malo al inicio se presentaba como las consecuencias de las acciones: lo útil/ lo inútil.

- Lo bueno/ lo malo posteriormente fueron interpretados como cualidades de las acciones.

- Lo bueno/ lo malo vistos como motivos, intenciones de las acciones (no cualidades).

- Lo bueno/ lo malo entendidos como el ser del hombre que produce los motivos.

Esto daba como consecuencia la ilusión de que el hombre decide; 
sin embargo, como se deduce de lo planteado anteriormente, eso no es así.

Debo aclarar aquí la idea de Nietzsche acerba de la "inocencia" humana. El cuerpo crea las acciones al margen de la conciencia, pero el hombre puede, por una parte, "oyendo" a su cuerpo, crear sus propios valores $y$, por otra parte, modificar su cuerpo mediante la coacción de la moral que él se da a sí mismo. Es decir, que la "inocencia" no implica pasividad. El hombre puede y debe crearse en un cierto sentido de la palabra. Pero, a diferencia de lo que expresa Kant, no se emancipa del yugo de la naturaleza, porque la moral actúa en el cuerpo y desde la razón como producto del cuerpo ${ }^{3}$. Por otra parte, ese imperativo que se da el hombre a sí mismo no es categórico, sino hipotético, pues el hombre debe darse órdenes no por deber, sino para no sucumbir como especie. La moral es como la fina

3. Ciertamente, en el parágrafo 19 de Humano demasiado humano, Nietzsche dice que Kant está en lo correcto al decir que la razón no toma sus leyes de la naturaleza sino que las prescribe a ésta, pero sólo en cuanto a la naturaleza como representación humana, no a la naturaleza real, inalcanzable para nuestra razón (lo dionisíaco, la voluntad, lo inconsciente). Aunque en Kant la naturaleza como representación es la única que existe para nosotros, en Nietzsche la realidad no conceptual, desconocida para nosotros, existe y es la que nos determina. gubia del tallador o la presión de las manos del alfarero; con ella, el hombre debe crearse y perfeccionarse, darse forma, a costa de infrigirse dolor y presión. La moral no debe ser valorada en sí misma, pues por sí sola es limitadora de las fuerzas vitales, sino como medio de potenciación de estas fuerzas. "Lo que no me mata, me hace más fuerte", es aplicado también aquí: la moral es una disciplina para que el ser humano y su especie puedan evolucionar (mejorar las condiciones de su corporalidad). También la moral es un medio para lograr las "cosas por las que vale la pena vivir": "virtud", arte, música, baile, razón, espiritualidad".

\section{Contra el imperativo categórico}

Ya desde el apartado anterior vemos que Nietzsche se revela contra lo categórico del imperativo. Todo lo que se haga, se hace siempre como medio y no como un fin en sí mismo. "En la realidad faltan fines"...

Por otra parte, rechaza también lo categórico de la intención en las llamadas "acciones por deber". En primer lugar las intenciones nunca son puras. Son signos y síntomas que necesitan interpretarse.

4. Interpreto: destreza. 
La intención es sólo una superficie bajo la cual se esconde lo "no intencionado" que es lo que constituye verdaderamente el valor de una acción. Así que si yo racionalmente tomo decisiones "por deber" los motivos irracionales que me impulsan a actuar de esta manera, de los que soy inconsciente, son los verdaderos artífices de mi acción.

Allí se quiebra también el carácter de impersonalidad que intentó dar Kant al imperativo. Cada moral es el producto de su cuerpo y el imperativo categórico dice mucho acerca de quien lo produce. Nietzsche dice que no hay una moral, sino una pluralidad de ellas y que cada una es diferente en cada moralista. Incluso dos personas con principios idénticos tienen diferentes motivos e intenciones. También critica Nietzsche, en general, a los filósofos de la moral ${ }^{5}$ (y a Kant en tanto que el imperativo categórico debe hacer abstracción a los intereses personales), los presuntos sentimientos de abnegación, sacrificio por el prójimo, la renuncia a sí, y toda esa "estética de la contemplación desinteresada". La renuncia a sí mismo, tanto como el intento de despersonalizar las acciones morales, son síntomas de la decadencia de fuerzas vitales. Tal imperativo no hace resplandecer

5. Como reacción a su antiguo maestro Schopenhauer. la vida, ni mejora la raza humana, sino que asfixia la voluntad de vida que se expresa en el egoísmo. Éste, así como el provecho propio y el placer, son condenados en la moral, tanto la religiosa como la kantiana, como motivos no morales, o hasta inmorales. Para Nietzsche, éstos son los impulsos necesarios para la construcción de una moralidad potenciadora de vida. Quizá haya que proponerse deberes que, aun ahora, se han considerado "malos": interesados, egoístas.

Nietzsche entiende el imperativo categórico kantiano como una imposición de Kant de su propio imperativo a todos los demás:

Kant (...) reclama de cada individuo acciones que desearía realizasen todos los demás. (Nietzsche, 1962:25)

Lo que en mí es respetable es el hecho de que yo puedo obedecer, _iy en vosotros las cosas no deben ser diferentes que en mí! (Nietzsche, 1984:187)

Para Nietzsche el imperativo kantiano es un peligro para la especie, por el hecho de que Kant intenta igualar las acciones de todos y universalizarlas, cortarlas con un único patrón (lo cual sería limitar el individuo y despersonalizar su acción: y eso conlleva la decadencia de los instintos). Cada quien, 
irrumpe Nietzsche con violencia, ha de crear su moral propia, $s u$ virtud.

Probablemente Nietzsche no haya sido justo en este punto. A mi parecer, Kant no intenta pasar a todos por el mismo rasero, sino hacer concientizar a cada cual sus acciones. Cada individuo se erige en creador de su propia moral. Pero en Kant esta creación debe ser universalizable para ser compatible con las de los demás; en cambio, en Nietzsche lo universal es falso y la universalización es la homologación de las diferencias lo cual equivale a la muerte de la individualidad y de su fuerza vital.

\section{El chino}

Siempre ha llamado la atención el "apodo" con el que Nietzsche designa frecuentemente a Kant. Y si "chino" significa "mediocre" ¿en qué consiste tal mediocridad kantiana?

Nietzsche expresa que Kant fue "un gran crítico", pero era "¡únicamente eso!” Sin embargo, un filósofo no sólo ha de ser crítico, sino que su visión debe ser lo más amplia posible:

Él mismo [el filósofo] tiene que haber sido tal vez crítico y escéptico y dogmático e historiador y, además, poeta y coleccionista y viajero $y$ adivinador de enigmas y moralista $y$ vidente $y$ "espiritu libre" y casi todas las cosas, a fin de recorrer el círculo entero de los valores y de los sentimientos valorativos del hombre a fin de poder mirar con muchos ojos y conciencias desde la altura hasta toda lejanía, desde profundidad hacia toda altura, desde el rincón, hacia toda la amplitud. (Nietzsche, 1962)

Y todo eso para tener la grandeza y la experiencia necesaria para poder crear sus propios valores. Kant ha sido el gran "lenguado" de la filosofía: su punto de vista es unilateral: filosófico-catedrático, königsberguense, célibe, de perpetua paz y caminatas a la misma hora por el mismo recorrido limitado. Kant es un buen crítico, es decir, buen destructor, pero con ello hace la mitad del camino, ya que es necesario erigir nuevos edificios y no botar los viejos y luego, a falta de otros, volverlos a desempolvar.

Aquellos trabajadores filosóficos modelados según el noble patrón de Kant y de Hegel tienen que establecer y que reducir a fórmulas cualquier gran hecho efectivo de valoraciones_ es decir, de anteriores posiciones de valor (...). A estos investigadores les incumbe el volver aprensible, manejable, dominable con la mirada, dominable con el pensamiento todo lo que hasta ahora ha ocurrido y ha sido objeto de aprecio (...): inmensa y maravillosa tarea de la que pueden sentirse satisfechos con seguridad todo 
orgullo sutil, toda voluntad tenaz. (Nietzsche, 1984:211)

Pero los "verdaderos filósofos" son creadores a partir de estas experiencias; todo lo que existe es para ellos un medio para la creación. Los filósofos mencionados son los grandes señores del pensamiento, pero sus creaciones, según Nietzsche, no son sino reformulaciones de los mismos valores con un mayor grado de concientización. Lo problemático de aquí es saber qué significa para Nietzsche "crear"... Pienso que el error de los críticos es el haber permanecido en el mundo conceptual, "ideal", y no haber puesto los pies en la tierra como luego les reclamará Marx y los materialistas ${ }^{6}$. Crear, podría significar crear desde el cuerpo propio, desde el instinto. Es decir, ser consciente de lo que uno es, de su cuerpo, de las posibilidades y limitaciones que este tiene, de sus virtudes $\mathrm{y}$ defectos y de cómo puede usarlos. Por ejemplo, si predomina en mí un instinto sexual, no eliminarlo,

6. Andrea Díaz en su artículo Kant versus Nietzsche, hace una singular analogía, dice que Nietzsche es a Kant como Marx es a Hegel, aunque los resultados sean bien disímiles. Algo hay de razón en esta comparación, pues mientras Marx pone la filosofía de Hegel en la tierra invirtiendo las relaciones entre los material e ideal, algo similar ocurre cuando Nietzsche "transvalora" los valores racionalistas de Kant, situando la razón en la dependencia del cuerpo. sino elevarlo a la categoría de valor y crear desde este, poemas, filosofía, arte. Si la sed de venganza y el odio me desbordan, usar esa fuerza destructiva para construirme a mí mismo. Tampoco negar la pluralidad del propio ser. Un ejemplo de un filósofo "verdadero" en el sentido nietzscheano, podría ser un hombre universal como Da Vinci que cultivó en sí cuanta inclinación encontró y no se negó dimensiones disímiles de su inclinación principal, enriqueciendo así también a esta. De lo cual no se sigue necesariamente que Kant debería ser pintor. Aún se pueden oír las carcajadas de Nietzsche al pensar en Sócrates intentando ser músico. Esa pluridimensionalidad debe estar en la posibilidad de incorporarla en el pensamiento, de poder mirar el mundo desde múltiples perspectivas y ser consciente, a la vez de que ninguna de ellas es más válida que la otra, solo son interpretaciones, variaciones a un tema inexistente por sí mismo.

Y éste, según Nietzsche, tal vez es el fallo más importante de la filosofía kantiana: su unilateralidad y su esterilidad ${ }^{7}$, que bien podrían ser producto de su celibato.

7. Cuando Nietzsche dice "El varón es, en efecto, dicho sea con permiso, un animal estéril" (Más allá del bien y del mal, Sentencias e interludios, 144) quiere decir que la mujer, que está biológicamente predispuesta para crear 


\section{Bibliografía}

Díaz, Andrea. (2004). Nietzsche (1884$1900)$ versus Kant (1724-1804) Recuperado el 11 de noviembre de 2011 de http://www.fhuce.edu.uy/public/actio/ Textos/5/AndreaDiaz.pdf

Kant, Immanuel. (1984). Crítica de la razón práctica. Alfaguara. Buenos Aires.

Navarro, Juan Manuel; Calvo, Tomás. (1990). Historia de la filosofía. Anaya. Madrid.

Nietzsche, Friedrich. (2000). Así habló Zaratustra, Traducción: Andrés Sánchez Pascual. Alianza. Madrid.

Nietzsche, Friedrich. (1986). El Anticristo, Traducción: Andrés Sánchez Pascual. Alianza. Madrid.

Nietzsche, Friedrich. (1984). El crepúsculo de los ídolos. Traducción: Andrés Sánchez Pascual. Alianza. Madrid.
Nietzsche, Friedrich. (2000). El nacimiento de la tragedia, Traducción: Andrés Sánchez Pascual. Alianza. Madrid.

Nietzsche, Friedrich. (1962). Humano, demasiado humano. Aguilar. Buenos Aires.

Nietzsche, Federico. (1984). La gaya ciencia. Editores Mexicanos Unidos. México.

Nietzsche, Friedrich. (1984). Más allá del bien y del mal. Traducción: Andrés Sánchez Pascual. Alianza. Madrid.

Nietzsche, Friedrich (1970). Sobre verdad y mentira en sentido extramoral, Obras Completas, Vol. I. Ediciones Prestigio. Buenos Aires.

Palmquist, Steve. (s.f.). How "chinese" was Kant? Recuperado el 11 de noviembre del 2011 de http://www.the-philosopher.co.uk/chinese.htm.

vida a partir de su propio cuerpo, tiene una ventaja sobre el varón que, grosso modo, no posee esta cualidad. En un sentido nietzscheano, ser estéril es no saber crear desde el cuerpo, sino desde la razón a la que considera castrante, en cuanto que actúa como limitante, cohibidora de lo corporal. Para Nietzsche el filósofo debería tomar el ejemplo en la mujer y producir sus ideas como una "hembra embarazada", según las condiciones del cuerpo. Es por eso el filósofo racional, como Kant, "dicho sea con permiso, es un animal estéril". 
